\title{
Pengaruh Intensitas Penyiraman terhadap Persemaian Cabai Rawit (Capsicum frutescens L.) dengan Media Semai Pelepah Batang Pisang di Kelompok Tani Morgo Utomo Kelurahan Bence Kecamatan Garum, Kabupaten Blitar, Provinsi Jawa Timur
}

\section{(The Effect of Flowering Intensity on The Fueling of Cabai Rawit (Capsicum frutescens L.) with Media Everything was The Banana Stone in Kelompok Tani Morgo Utomo Kelurahan Bence Kecamatan Garum, Kabupaten Blitar, East Java Province)}

\author{
Zainatu Lutfiana ${ }^{1 *}$, Latarus Fangohoi ${ }^{1}$, dan Muhammad Saikhu ${ }^{1}$ \\ 1) Jurusan Penyuluhan Pertanian Berkelanjutan, Politeknik Pembangunan Pertanian Malang \\ J1. Dr. Cipto No.144A, Bedali-Lawang, Malang \\ *Email Korespondensi: lutfianazaina@gmail.com
}

Diterima 17 Juli 2019 / Disetujui 03 September 2019

\begin{abstract}
The purpose of this study was to determine the effect of the use of banana stem midrib as a medium for seedlings of cayenne pepper (Capsicum frutescents L.). The research was conducted on March 19, 2019 until April 15, 2019, in Bence, Garum, Blitar. The study was conducted using the Randomized Block Design (RBD) method which consisted of 4 treatments and 6 replications. The treatment used is the watering intensity of the cayenne seedbed, as follows: (CO). Without watering; (C1). Watering once a day; (C2). Watering twice a day and (C3). Watering 3 times a day. The parameters observed were plant height, leaf number and leaf color with 5 days observation interval. The results of this study indicate that banana stem midrib can be used as a medium for cayenne pepper seedlings. Based on observations, treatment (C1) shows the best results. This can be seen from the results of observations on the parameters at the end of the study (27 HSS), which include: the average plant height of $13.6 \mathrm{~cm}$ and the average number of leaves 4 strands. The use of banana stem midrib has an influence on the watering intensity of the seedlings of cayenne pepper (Capsicum frutescents L.). The best watering intensity is in C1 treatment with watering once a day.
\end{abstract}

Keywords: raw chili, banana stem fronds, watering, nursery

\section{ABSTRAK}

Tujuan dari penelitian ini adalah untuk mengetahui penggaruh penggunaan pelepah batang pisang sebagai media semai cabai rawit (Capsicum frutescents L.). Penelitian dilaksanakan pada tanggal 19 Maret 2019 sampai dengan tanggal 15 April 2019, di Kelurahan Bence, Garum, Blitar. Penelitian dilakukan dengan menggunakan metode Rancangan Acak Kelompok (RAK) yang terdiri dari 4 perlakukan dan 6 kali ulangan. Perlakuan yang digunakan adalah intensitas penyiraman terhadap persemaian cabai rawit, sebagai berikut: (CO). Tanpa penyiraman; (C1). Penyiraman 1 kali sehari; (C2). Penyiraman 2 kali sehari dan (C3). Penyiraman 3 kali sehari. Parameter yang diamati adalah tinggi tanaman dan jumlah daun dengan interval pengamatan 5 hari. Hasil dari penelitian ini menunjukkan bahwa pelepah batang pisang bisa digunakan sebagai media semai cabai rawit. Berdasarkan hasil pengamatan, perlakuan (C1) menunjukkan hasil yang terbaik. Hal ini terlihat dari hasil pengamatan terhadap parameter pada akhir penelitian (27 HSS), yang meliputi: rata-rata tinggi tanaman sebesar 13,6 cm dan rata-rata jumlah daun 4 helai. Penggunaan pelepah batang pisang memberikan pengaruh terhadap intensitas penyiraman pada persemaian cabai rawit (Capsicum frutescents L.). Intesitas penyiraman terbaik adalah pada perlakuan C1 dengan penyiraman 1 kali sehari.

Kata Kunci: cabai rawit, pelepah batang pisang, penyiraman, persemaian

\section{PENDAHULUAN}

Indonesia dikenal sebagai negara agraris dan juga dikenal sebagai negara yang menjadi pusat asal-usul dari pisang yang ada di dunia. Pada tahun 2018 Indonesia menempati posisi ke-7 dunia sebagai negara produsen pisang. Indonesia termasuk negara yang berperan penting dalam bidang penanaman pisang di daerah Asia. Indonesia mampu menjadi produsen dan memenuhi kebutuhan $50 \%$ pisang di daerah Asia. Jumlah produksi pisang di Indonesia sebesar 7,29 juta ton pada tahun 2015 (BPS, 2015). Pusat produksi pisang di Indonesia sendiri paling banyak berada di wilayah Sumatra, Jawa, dan Bali. 
Pulau Jawa adalah salah satu daerah yang menyumbang produksi pisang terbesar setelah Sumatra. Daerah yang menghasilkan pisang adalah Jawa Barat, JawaTengah dan Jawa Timur. Di Jawa Timur sendiri pisang yang paling banyak di hasilkan adalah jenis pisang agung dan pisang kepok. Salah satu Kabupaten yang memliki produksi pisang jenis kepok adalah Kabupaten Blitar. Di Kabupaten Blitar ada beberapa Kecamatan yang memiliki produksi pisang salah satunya yaitu di Kecamatan Garum.

Kecamatan Garum teretak di sebelah timur kota Blitar, tepatnya berada di lembah dan lereng Gunung Kelud. memiliki luas 5.563,10 Ha. terletak pada 111- 10' Bujur Timur dan 7 58-8 9,5 “ Lintang Selatan, dengan batas wilayah sebagai berikut: sebelah barat berbatasan dengan Kecamatan Nglegok dan Kota Blitar, sebelah selatan berbatasan dengan Kecamatan Kanigoro, sebelah utara berbatasan dengan Gunung Kelud Kabupaten Kediri, sebelah timur berbatasan dengan Kecamatan Gandusari dan Kecamatan Talun. Potensi yang ada di Kecamatan Garum yaitu banyaknya tanaman pisang.

Data Badan Pusat Statistik Kabupaten Blitar menunjukkan bahwa jumlah rumah tangga di Kecamatan Garum yang mengusahakan atau memiliki pohon pisang sendiri sebanyak 4.515 keluarga (BPS Kabupaten Blitar, 2015). Sesuai dengan jumlah rumah tangga tersebut banyaknya pohon pisang yang ditanam pada tahun 2015 sebanyak 9.035 pohon yang menghasilkan sebanyak 8.310 pohon (BPS Kabupaten Blitar 2016) maka dapat diketahui bahwa produksi limbah batang pisang sesuai dengan jumlah produksi tandan buah pisang yang dihasilkan. Karena setiap satu tandan pisang dihasilkan dari satu pohon pisang yang berarti juga menghasilkan limbah berupa satu batang pisang.

Selain tumbuh sebagai tanaman liar, tanaman pisang juga banyak dibudidayakan. Jenis pisang biasanya memiliki nama tersendiri berdasarkan kekhasan masing-masing. Jenis pisang yang telah familiar seperti pisang ambon, pisang nangka, pisang mas, pisang klutuk, pisang tanduk, pisang hias, pisang kepok dan lain-lainnya. Berbagai pisang tumbuh di Kecamatan Garum, ada pisang konsumsi yang bisa langsung dimakan, pisang yang harus diolah terlebih dahulu sebelum dikonsumsi, pisang berbiji, pisang serat, ada pula tanaman pisang yang hanya dijadikan hiasan di pekarangan rumah. Semua tanaman pisang tersebut dapat tumbuh subur di Kecamatan Garum. Terbukti hampir di setiap tempat dapat dengan mudah ditemukan tanaman pisang, baik yang dipelihara di pekarangan rumah ataupun tumbuh liar di pinggiran jalan. Tanaman pisang dapat dijumpai di segala pelosok tanah air, ditanam oleh manusia untuk diambil buahnya. Sebagai tanaman pangan (buah-buahan) pisang memiliki nilai ekonomis yaitu dapat tumbuh dengan cepat, berbuah pada umur rata-rata 1 tahun dan cepat berkembang biak (Cahyono, dalam Nurwahijab (2016).

Pelepah batang pisang merupakan salah satu jenis limbah yang banyak dihasilkan dari bagian batang pisang di perkebunan pisang. Batang pisang selama ini dianggap sebagai limbah yang tidak memiliki nilai ekonomi yang tinggi. Selama ini batang pisang hanya dibuang begitu saja tanpa adanya pemanfaatan lebih lanjut. Limbah yang berasal dari batang pisang merupakan limbah yang dapat diurai oleh tanah. Limbah seperti ini sangat baik bagi pertumbuhan tanaman karena merupakan limbah yang mudah terurai atau terdekomposisi dengan mudah.

Selama ini pemanfaatan limbah batang pisang belum dilakukan dengan maksimal. Pemanfaatan masih sebatas pada penggunaan sebagai pakan ternak saja. Salah satu pemanfaatan dari limbah batang pisang ini adalah dengan menggunakannya sebagai media semai dari tanaman cabai rawit yang diambil dari pelepahnya. Petani tidak mengetahui manfaat batang pisang bagi tanaman khususnya penggunaannya sebagai media semai. Petani terbiasa menyemai cabai rawit dengan menggunakan polibag kecil yang sudah diisi dengan campuran pupuk kandang dan tanah, hal ini dirasa cukup membebankan biaya untuk pembelian polibag sebagai media semai. Selain menekankan pada biaya, penggunaan polibag juga dapat meningkatkan produksi sampah plastik yang dapat merusak kesuburan tanah dan juga harus menjaga intensitas penyiraman agar tanah tetap terjaga kelembaban sehingga benih yang disemai mampu tumbuh dengan baik.

Batang pisang digunakan sebagai media semai untuk tanaman cabai rawit karena dengan menggunakan batang pisang tidak perlu melakukan penyiraman terlalu sering karena di dalam batang pisang mengandung banyak air yang selalu membasahi tanaman sehingga intensitas penyiraman bisa berkurang. Batang pisang sendiri diketahui mengandung air $96 \%$ lebih banyak yang sangat menjanjikan sebagai media semai sayur (Pandia, 2017). Keunggulan lain dari batang pisang ini diantaranya mengandung banyak pati, yang berfungsi sebagai sumber nutrisi tanaman dan juga mengandung mikroorganisme didalamnya yang akhirnya menjadi kompos. Selain itu, batang pisang juga memliki senyawa penting seperti Tanin, Saponin dan Flavonoid. Peran dari senyawa Saponin menghambat pertanaman jamur sehingga menghambat tanaman dari serangan serangga (Pangestika, 2017).

Oleh karena itu, pemanfaatan batang pisang khususnya pelepah batang pisang sebagai media semai pada tanaman cabai rawit dapat menguntungkan baik dari segi ekonomi, teknis dan sosial. Pemanfaatan pelepah batang pisang ini dapat mengurangi adanya limbah yang semula tidak digunakan menjadi barang yang berharga dimana pelepah batang pisang digunakan sebagai media semai. Pembuatan media semai akan dilakukan di kelompoktani Margo Utomo yang terletak di Kelurahan Bence Kecamatan Garum Kabupaten Blitar. Pembuatan media semai dari pelepah batang pisang ini sebagai pemecahan masalah dimana banyak terdapat limbah batang pisang yang tidak digunakan menjadi sebuah media semai yang sangat menguntungkan apabila diterapkan pada tanaman hortikultura khususnya cabai rawit yang merupakan komoditas unggulan di Kecamatan Garum.

\section{BAHAN DAN METODE}

Penelitian dilaksanakan di Kelurahan Bence, Kecamatan Garum, Kabupaten Blitar, Jawa Timur. Penelitian dilaksanakan pada 19 Maret 2019 sampai dengan 15 April 2019. Metode penelitian yang digunakan dalam penelitian ini 
adalah Rancangan Acak Kelompok (RAK), dimana intensitas penyiraman sebagai faktor pengamatan. perlakuan pada penelitian ada 4 dan diulang $6 \mathrm{kali}$, yaitu $\mathrm{C} 0=$ kontrol (tanpa penyiraman), $\mathrm{C} 1=$ penyiraman 1 kali sehari, $\mathrm{C} 2=$ penyiraman 2 kali sehari, dan C3 = penyiraman 3 kali sehari.

Pengamatan pertumbuhan dilakukan dengan mengambil 12 sampel tanaman pada umur 7, 12, 17, 22, 27 hari setelah semai. Pengamatan dengan mengukur tinggi tanaman dan jumlah daun. Data yang diperoleh dianalisis dengan Analisis Sidik Ragam taraf $5 \%$, apabila terjadi beda nyata antar perlakuan maka dilanjut dengan uji BNT 5\%.

\section{HASIL DAN PEMBAHASAN}

\section{Tinggi Tanaman}

Hasil Analisis Sidik Ragam menunjukkan bahwa F hitung perlakuan lebih besar dari $F$ tabel $(0,05)$, artinya terdapat perbedaan yang nyata karena persemaian menggunakan pelepah batang pisang terhadap tinggi tanaman cabai rawit pada semua pengamatan. Pengamatan dilakukan dengan interval 5 hari, rata-rata tinggi tanaman dan hasil uji BNT pada semua pengamatan dapat disajikan pada Tabel 1 .

Pada Tabel 1 menunjukkan bahwa penggunaan pelepah batang pisang sebagai media semai untuk tanaman cabai rawit berpengaruh nyata pada tinggi tanaman. Intensitas penyirmaan 1 kali sehari air dapat diserap dengan baik oleh tanaman dan tanah masih mampu menyediakan ketersediaan air karena pada pelepah batang pisang mengandung air. Hal ini disebabkan karena pada masa pertumbuhan tersebut akarakar tanaman masih relatif kecil, sehingga tidak membutuhkan suplai air dalam jumlah yang banyak, dalam kondisi ini tanaman masih mampu menyediakan kebutuhan air dalam kondisi optimal (Sukarman, 2012).

Perlakuan dengan penyiraman 1 kali sehari lebih baik dari perlakuan penyiraman 2 kali ataupun 3 kali sehari karena pada perlakuan ini rentan terjadi busuk akar karena keadaan akar yang terlalu lembab. Karena pelepah batang pisang memiliki pengaruh untuk mendukung pertumbuhan persemaian cabai rawit, mengingat bahwa terdapat kandungan air yang dapat membantu pertumbuhan tanaman. Pada tanaman dengan intensitas penyiraman yang sering dapat terjadi pembusukan akar dalam tanah karena akar menyerap air lebih banyak sehingga menyebabkan tanaman kerdil dan layu (Sari, 2016).

\section{Jumlah Daun}

Hasil Analisis Sidik Ragam menunjukkan bahwa F hitung perlakuan lebih besar dari $\mathrm{F}$ tabel $(0,05)$, artinya terdapat perbedaan yang nyata karena penggunaan pelepah batang pisang sebagai media semai terhadap jumlah daun cabai rawit pada semua pengamatan. Pengamatan dilakukan dengan interval 5 hari, dimulai dari munculnya daun yang sudah sempurna yakni pada hari ke 12 Hari Setelah Semai (HSS).

Pada Tabel 2 menunjukkan bahwa penggunaan pelepah batang pisang sebagai media semai tanaman cabai rawit berpengaruh nyata pada pertumbuhan jumlah daun. Hasil pengamatan menunjukkan bahwa perlakuan $\mathrm{C} 1$ memiliki perbedaan yang nyata jumlah daunnya pada pengamatan 12 HSS dan 27 HSS dan pertumbuhannya lebih baik dari perlakuan $\mathrm{C} 0, \mathrm{C} 2$ dan $\mathrm{C} 3$ karena keadaan kelembapan tanah yang baik.

Tabel 1 Tinggi Tanaman pada Persemaian Cabai Rawit dengan Perlakuan Intensitas Penyiraman

\begin{tabular}{cccccc}
\hline \multirow{2}{*}{ Perlakuan } & \multicolumn{5}{c}{ Rerata Tinggi Tanaman $(\mathbf{c m})$ pada Umur Pengamatan $($ HSS $)$} \\
\cline { 2 - 6 } & 7 HSS & 12 HSS & $\mathbf{1 7 ~ H S S}$ & $\mathbf{2 2 ~ H S S}$ & $\mathbf{2 7}$ HSS \\
\hline C0 & $0,21 \mathrm{a}$ & $0,38 \mathrm{a}$ & $0 \mathrm{a}$ & $0 \mathrm{a}$ & $0 \mathrm{a}$ \\
C1 & $0,61 \mathrm{~b}$ & $2,62 \mathrm{~b}$ & $6,67 \mathrm{c}$ & $9,01 \mathrm{c}$ & $13,67 \mathrm{c}$ \\
C2 & $0,51 \mathrm{~b}$ & $2,50 \mathrm{~b}$ & $5,94 \mathrm{~b}$ & $7,74 \mathrm{bc}$ & $12,16 \mathrm{bc}$ \\
C3 & $0,55 \mathrm{~b}$ & $2,6 \mathrm{~b}$ & $6,63 \mathrm{c}$ & $8,74 \mathrm{c}$ & $13,46 \mathrm{c}$ \\
\hline BNT 5\% & 0,290 & 0,560 & 0,311 & 0,663 & 0,972 \\
\hline
\end{tabular}

Keterangan: Bilangan yang didampingi huruf yang sama pada umur yang sama menunjukkan tidak beda nyata berdasarkan uji BNT 5\%.

Tabel 2 Jumlah Daun pada Persemaian Cabai Rawit dengan Perlakuan Intensitas Penyiraman

\begin{tabular}{ccccc}
\hline \multirow{2}{*}{ Perlakuan } & \multicolumn{4}{c}{ Rerata Jumlah Daun (helai) pada Umur Pengamatan (HSS) } \\
\cline { 2 - 5 } & 12 HSS & 17 HSS & 22 HSS & 27 HSS \\
\hline C0 & $0 \mathrm{a}$ & $0 \mathrm{a}$ & 0 & $0 \mathrm{a}$ \\
C1 & $2,06 \mathrm{~d}$ & $2,22 \mathrm{~b}$ & 3,86 & $4,47 \mathrm{c}$ \\
C2 & $1,99 \mathrm{~b}$ & $2,14 \mathrm{~b}$ & 3,63 & $4,08 \mathrm{bc}$ \\
C3 & $2,01 \mathrm{c}$ & $2,17 \mathrm{~b}$ & 3,92 & $4,26 \mathrm{~b}$ \\
\hline BNT 5\% & 0,007 & 0,550 & tn & 0,121 \\
\hline
\end{tabular}

Keterangan: Bilangan yang didampingi huruf yang sama pada umur yang sama menunjukkan tidak beda nyata berdasarkan uji BNT 5\%. 
Bibit siap tanam adalah bibit yang mempunyai 3-4 helai daun sejati dengan umur 21-30 HSS (Prajnanta dalam Wahyudi, 2014) Selaras dengan asumsi tersebut, pemberian air yang telalu sering menyebabkan pertumbuhan tanaman cabai yang optimal, dan tidak bermanfaat serta tidak efisien dalam penggunaan air (Kusumawati, 2016).

\section{KESIMPULAN}

Penggunaan pelepah batang pisang memberikan pengaruh terhadap intensitas penyiraman pada persemaian cabai rawit (Capsicum frutescens L.). Sesuai dengan keseluruhan hasil pengamatan menggunakan parameter tinggi tanaman dan jumlah daun dengan Analisis Sidik Ragam dan uji lanjut BNT 5\% dapat diketahui bahwa penggunaan pelepah batang pisang berpengaruh nyata terhadap pertumbuhan persemaian cabai rawit. Perlakuan C1 memberikan hasil yang terbaik. Dibuktikan dengan perlakuan yang diberikan intensitas penyiraman lebih banyak memiliki pertumbuhan tanaman yang tidak lebih bagus dengan yang diberikan intensitas penyiraman 1 kali sehari karena kandungan air pada pelepah batang pisang dapat membantu pertumbuhan tanaman.

\section{DAFTAR PUSTAKA}

BPS. 2015. Jumlah Rumah Tangga Usaha Hortikultura Jumlah Pohon Rumpun Luas Tanam dan Rata-Rata Jumlah Pohon Rumpun Luas Tanam yang Diusahakan Dikelola Per Rumah Tangga Menurut Jenis Tanaman Hortikultura Tahunan. https://blitarkab.bps.go.id/. [15 Desember 2018]

BPS. 2015. Produksi Pisang Di Indonesia. https://www.bps.go.id/. [15 Desember 2018]
BPS. 2016. Kecamatan Garum Dalam Angka 2016. Katalog BPS. 1403. 3505. 160. Blitar

Nurwahijab. 2016. Kandungan Ndf (Neutral Detergent Fiber) dan Adf (Acid Detergent Fiber) Silase Pakan LengSkap Berbahan Utama Batang Pisang (Musa Paradisiaca) Dengan Lama Fermentasi Yang Berbeda.

Pandia, Ekarian S, et. al. 2017. Pemanfaatan Limbah Batang Pisang seagai Media Tanam di Desa Peunaron Lama Kecamatan Peunaron Kabupten Aceh Timur. Jurnal Jeumpa, 4 (1)- Juni 2017.

Pangestika, Rike. 2017. Efektivitas Getah Batang Semu Pisang Ambon (Musa acuminata) dan Getang Batang Semu Pisang Kepok (Musa balbisiana) pada Penyembuhan Luka Bakar Mencit (Mus musculus). Yogyakarta (ID): Universitas Sanata Dharma:

Sari, Rifa Meri Puspita, DKK. 2016. Pengaruh Frekuensi Penyiraman dan Dosis Pupuk Kandang Ayam. Terhadap Pertumbuhan dan Hasil Tanaman Pakchoy (Brassica rapa L. var. chinensis). Jurnal Produksi Tanaman Vol. 4 No. 5, Juli 2016: 342-351.

Sukarman, H.I., Ja'far., A.T. Josephus. I. Kalangi dan M.T. Lasut. 2012. Pengaruh Frekuensi Air terhadap Pertumbuhan Bibit Jabon Merah (Anthocephalus macrophyllus (Roxb.) Havil). Manado.

Wahyudi, I., dan Abror. 2014. Pengaruh tinggi dan jenis bahan naungan pembibitan terhadap vigor cabai merah besar (Capsicum annum L.). Nabatia, 11(1). 